\title{
Family Physicians' Role in Simplifying Medication Abortion During the COVID-19 Pandemic
}

\author{
Payal Patel, MD, Sumathi Narayana, MD, MS, Zoey Thill, MD, MPP, MPH, \\ Marji Gold, MD, and Allison Paul, MD, MPH
}

Despite first trimester abortion being common and safe, there are numerousrestrictions that lead to barriers to seeking abortion care. The COVID-19 pandemic hasonly exacerbated these barriers, as many state legislators push to limit abortion accesseven further. During this pandemic, family physicians across the country haveincorporated telemedicine into their practices to continue to meet patient needs.Medication abortion can be offered to patients by telemedicine in most states, andmultiple studies have shown that labs, imaging, and physical exam may not beessential in all cases. Family physicians are well-poised to incorporate medicationabortion into their practices using approaches that limit the spread of the coronavirus, ultimately increasing access to abortion in these unprecedented times. (J Am Board Fam Med 2021;34:S33-S36.)

Keywords: Abortion Applicants, COVID-19, Family Physicians, Induced Abortion, Pandemics, Pregnancy, First Trimester, Telemedicine

\section{Introduction}

First-trimester abortion is one of the most common outpatient medical procedures in the United States. It is extremely safe and represents more than $90 \%$ of all abortions that occur in the United States. ${ }^{1,2}$ Medication abortion, which involves taking the pills mifepristone and misoprostol to end a pregnancy, entails minimal interaction between patients and clinicians. It is approved by the Food and Drug Administration for use up to 10 weeks' gestation. Since mifepristone's introduction to the US market in 2000, medication abortion has become increasingly common and represents $39 \%$ of all abortions that occur in the United States annually. ${ }^{3}$ Complications are rare, and completion rates are between $97 \%$ and $98 \%{ }^{4}$

Even before the COVID-19 pandemic, patients seeking abortion care have faced decades of onerous legal barriers, institutional restrictions, and an

This article was externally peer reviewed.

From the Department of Family and Social Medicine, Albert Einstein College of Medicine/Montefiore Medical Center, Bronx, NY; and RHEDI-Mainstreaming Abortion in Family Medicine, New York, NY.

Funding: None.

Conflict of interest: None.

Corresponding author: Marji Gold, MD, Department of Family and Social Medicine, 3544 Jerome Avenue, Bronx NY 10467 (E-mail: marji.gold@einsteinmed.org). inadequate distribution of abortion providers throughout the United States. The most recent data on regional distribution of abortion facilities were published by the Guttmacher Institute and shows that $89 \%$ of US counties did not have a clinical facility that provides abortion in 2017. Furthermore, $38 \%$ of reproductive-aged women between the ages of 15 and 44 years lived in counties without any abortion-providing facility in 2017. ${ }^{1}$ Many states' governors use executive powers to limit abortion. With workforce demands shifting outpatient clinicians into the hospital, the COVID19 pandemic has exacerbated many of the oppressive barriers to abortion access that have existed for decades.

The consequences of the inability to access abortion have been well demonstrated. Pregnant people who are unable to obtain a wanted abortion are 4 times more likely than people who are able to obtain their abortion to live below the federal poverty level, are 3 times more likely to be unemployed, and are more likely to stay in contact with violent partners. They also experience more serious health problems. ${ }^{5,6}$

Practice models are evolving rapidly to accommodate essential and time-sensitive health care services in light of the COVID-19 pandemic. First-trimester abortion services are no exception. Abortion services 
have fundamentally changed in many clinical contexts in an effort to accommodate patients coping with quarantines, mandatory stay-at-home orders, limited transportation options, and changing work and family obligations. The goal of these changes is to safely limit the contact between patients and staff and ultimately limit the spread of the novel coronavirus "No-test" protocols provide recommendations for patient eligibility, ${ }^{7}$ evaluation of gestational age without clinical contact (eg, omitting sonogram and pelvic examination), ${ }^{8-10}$ limited Rh testing, ${ }^{1-13}$ and modified follow-up via "videoconference, telephone, patient portal, e-mail, text, or other telemedicine modalities." ${ }^{\text {,14-19 }}$ With screening and counseling done ahead of time, the "no-test" protocol eliminates the majority of contact between patients and staff. However, unlike other telemedicine care, in which the physician can send a prescription to the pharmacy, the Food and Drug Administration still requires clinicians to dispense mifepristone directly to patients in person.

Increasingly, telemedicine is being used to maintain and to improve critical access to essential services. As more primary care is being provided through telemedicine, family physicians are well poised to fill gaps in abortion access via this delivery model. Moreover, according to a 2018 National Academies of Sciences, Engineering, and Medicine report about abortion care in the United States, family physicians can provide abortions safely and effectively in the outpatient primary care setting. ${ }^{2}$ Medication abortion specifically draws on existing clinical skills of family physicians including pregnancy diagnosis counseling, medication management, clinical follow-up. ${ }^{20}$ It requires neither procedural training nor specialized equipment. In light of the COVID-19 pandemic, clinical sites are using the "no-test" protocol described above, making medication abortion counseling and followup ideal telemedicine visits.

A widespread adoption of medication abortion provision by family physicians using these simplified protocols could have a profound effect on access to abortion in the United States. Historically, family physicians practice in underserved areas of the country and provide care that is difficult to access. There are approximately 200,000 practicing primary care physicians in the United States, ${ }^{20}$ and workforce data show that family physicians are the most common specialty practicing in medically underserved areas of the United States. These areas also happen to be regions with the largest barriers to abortion care. ${ }^{21-23}$ Providing medication abortion is well aligned with the central tenets of family medicine, including the commitment to help reduce health care disparities. Medication abortion has success rates of $96.5 \%$ and $99.2 \% .^{24,25}$

Although family physicians are well poised to provide abortions, few do. Data from the 2018 and 2019 family medicine national graduate surveys of graduates 3 years out of residency showed that only $3.7 \%$ (172 of 4644) provided pregnancy terminations. Interestingly, of those who reported providing abortion care, almost half (40.7\%) indicated that they did not provide uterine aspiration/ dilation and curettage, likely signifying that they are performing only medication abortion (Table 1).

Whereas only $3.7 \%$ of recently graduated family physicians provide abortions, $13.3 \%$ report feeling prepared to provide abortion care based on training obtained in residency (Table 1). This discrepancy suggests the barriers are not limited to lack of education or training. Indeed, administrative and systems-level barriers in integrating abortion care

Table 1 Graduate Survey Data From Family Medicine Graduates 2018-2019, American Board of Family Medicine ${ }^{4}$

\begin{tabular}{llll}
\hline & $\begin{array}{c}\text { Provides pregnancy } \\
\text { termination }\end{array}$ & \multicolumn{1}{c}{ P value } & \\
\hline $\begin{array}{c}\text { Prepared for pregnancy termination upon } \\
\text { graduation from residency }\end{array}$ & Yes $(\mathrm{N}=172)$ & No $(\mathrm{N}=4,472)$ & Total $(\mathrm{N}=4,644)$ \\
Yes & $130(75.6 \%)$ & $489(10.9 \%)$ & $619(13.3 \%)$ \\
No & $42(24.4 \%)$ & $3983(89.1 \%)$ & $4025(86.7 \%)$ \\
$\begin{array}{l}\text { Provides uterine aspiration/D\&C } \\
\text { Yes }\end{array}$ & Yes $(\mathrm{N}=173)$ & No $(\mathrm{N}=4472)$ & $\begin{array}{l}\text { Total }(\mathrm{n}=4645) \\
\text { No }\end{array}$ \\
\hline
\end{tabular}

$\mathrm{D} \& \mathrm{C}$, dilation and curettage. 
were most frequently mentioned as reasons that respondents who intended to provide abortion are not currently doing so. ${ }^{26}$ Other barriers to medication abortion provision include stringent Food and Drug Administration regulations that require providers to register with a central database to dispense mifepristone to patients, strict medication-dispensing regulations that require a clinician to dispense the pills directly to the patient, concerns for safety of clinic staff and patients, personal beliefs, lack of insurance reimbursement, and lack of colleague support. $^{20,27,28}$

These barriers, like other elements of care provision, are evolving in light of the current COVID-19 pandemic and may not be present to the same extent in the future with new health care delivery methods. This time of transition marks an auspicious time to increase medication abortion delivery within family medicine. One in 4 women will have an abortion in their lifetime, and nearly every family physician will care for patients who can become pregnant. Now more than ever, medication abortion services and education should be championed within family medicine. This expansion of care is especially pertinent now, in a time of markedly decreased access to care, but changes adopted should continue into the future.

We thank Lars Peterson, MD, PhD, and Zachary Morgan, MS, from the American Board of Family Medicine in Lexington, $\mathrm{KY}$, for their assistance with data analysis and review of the manuscript.

To see this article online, please go to: http://jabfm.org/content/ 34/Supplement/S33.full.

\section{References}

1. Jones RK, Witwer E, Jerman J. Abortion incidence and service availability in the United States, 2017. New York: Guttmacher Institute; 2019.

2. National Academies of Sciences Eg, and Medicine, Health and Medicine Division, Board on Health Care Services, Board on Population Health and Public Health Practice, Committee on Reproductive Health Services: Assessing the Safety and Quality of Abortion Care in the U.S. (2018). The safety and quality of abortion care in the United States. Washington, DC: The National Academies Press.

3. Jones RK, Jerman J. Abortion incidence and service availability in the United States, 2014. Perspect Sex Reprod Health 2017;49:17-27.

4. Upadhyay UD, Desai S, Zlidar V, et al. Incidence of emergency department visits and complications after abortion. Obstet Gynecol 2015;125:175-83.
5. Foster DG, Biggs MA, Ralph L, Gerdts C, Roberts S, Glymour MM. Socioeconomic outcomes of women who receive and women who are denied wanted abortions in the United States. Am J Public Health 2018;108:407-13.

6. Ralph LJ, Schwarz EB, Grossman D, Foster DG. Self-reported physical health of women who did and did not terminate pregnancy after seeking abortion services: a cohort study. Ann Intern Med 2019;171:238.

7. Raymond EG, Grossman D, Mark A, et al. Commentary: No-test medication abortion: a sample protocol for increasing access during a pandemic and beyond. Contraception 2020;101:361-6. S0010-7824(0020)30108-30106.

8. Bracken H, Clark W, Lichtenberg ES, et al. Alternatives to routine ultrasound for eligibility assessment prior to early termination of pregnancy with mifepristone-misoprostol. BJOG 2011;118:17-23.

9. Constant D, Harries J, Moodley J, Myer L. Accuracy of gestational age estimation from last menstrual period among women seeking abortion in South Africa, with a view to task sharing: a mixed methods study. Reprod Health 2017;14:100.

10. Raymond EG, Bracken H. Early medical abortion without prior ultrasound. Contraception 2015;92:212-214.

11. Hollenbach SJ, Cochran $M$, Harrington A. "Provoked" feto-maternal hemorrhage may represent insensible cell exchange in pregnancies from 6 to 22 weeks gestational age. Contraception 2019; 100:142-146.

12. Horvath S, Tsao P, Huang ZY, et al. The concentration of fetal red blood cells in first-trimester pregnant women undergoing uterine aspiration is below the calculated threshold for Rh sensitization. Contraception 2020;102:1-6.

13. Wiebe ER, Campbell M, Aiken ARA, Albert A. Can we safely stop testing for $\mathrm{Rh}$ status and immunizing $\mathrm{Rh}$-negative women having early abortions? A comparison of Rh alloimmunization in Canada and the Netherlands. Contraception: X 2019;1:100001.

14. Chen MJ, Rounds KM, Creinin MD, Cansino C, Hou MY. Comparing office and telephone followup after medical abortion. Contraception 2016;94: 122-126.

15. Clark W, Bracken H, Tanenhaus J, Schweikert $S$, Lichtenberg ES, Winikoff B. Alternatives to a routine follow-up visit for early medical abortion. Obstet Gynecol 2010;115:264-272.

16. Endler M, Lavelanet A, Cleeve A, Ganatra B, Gomperts R, Gemzell-Danielsson K. Telemedicine for medical abortion: a systematic review. Bjog 2019;126:1094-1102.

17. Jackson AV, Dayananda I, Fortin JM, Fitzmaurice G, Goldberg AB. Can women accurately assess the outcome of medical abortion based on symptoms alone? Contraception 2012;85:192-197. 
18. Perriera LK, Reeves MF, Chen BA, Hohmann HL, Hayes J, Creinin MD. Feasibility of telephone follow-up after medical abortion. Contraception 2010;81:143-149.

19. Raymond EG, Tan YL, Grant M, et al. Self-assessment of medical abortion outcome using symptoms and home pregnancy testing. Contraception 2018; 97:324-328.

20. Beaman J, Schillinger D. Responding to evolving abortion regulations - the critical role of primary care. N Engl J Med 2019;380:e30.

21. Fink KS, Phillips RL, Fryer GE, Koehn N. International medical graduates and the primary care workforce for rural underserved areas. Health Aff (Millwood) 2003;22:255-262.

22. Fryer GE, Green LA, Dovey SM, Phillips RI Jr. The United States relies on family physicians unlike any other specialty. Am Fam Physician 2001;63:1669.

23. Phillips R, Dodoo M, Petterson S, et al. Specialty and geography distribution of the physician workforce: what influences medical student and resident choices? Robert Graham Center: Policy Studies in Family Medicine and Primary Care. 2009.2

24. Bennett IM, Baylson M, Kalkstein K, Gillespie G, Bellamy SL, Fleischman J. Early abortion in family medicine: clinical outcomes. Ann Fam Med 2009;7: 527-533.

25. Prine L, Lesnewski R, Berley N, Gold M. Medical abortion in family practice: a case series. J Am Board Fam Pract 2003;16:290-295.

26. Srinivasulu S, Maldonado L, Prine L, Rubin SE. Intention to provide abortion upon completing family medicine residency and subsequent abortion provision: a 5 -year follow-up survey. Contraception 2019;100:188-192.

27. Food and Drug Administration. Risk Evaluation and Mitigation Strategy (REMS) for single shared system mifepristone $200 \mathrm{mg}$. Washington (DC): Food and Drug Administration; 2019.3

28. Greenberg M, Herbitter C, Gawinski BA, Fletcher J, Gold M. Barriers and enablers to becoming abortion providers: the reproductive health program. Fam Med 2012;44:493-500. 